\title{
Papers
}

\section{Wall base damp: Is one horizontal damp-proof course sufficient dampness protection?}

Received (in revised form): 18th August, 2004

\section{Ralph Burkinshaw}

is a chartered building surveyor and visiting lecturer. He runs practical training on dampness investigation at chartered surveying practices. He is a truly independent dampness consultant, available to carry out inspections anywhere in the UK. He is also conducting one-day seminars on 'Dampness in Domestic Buildings' for SAVA, in 2005.

\begin{abstract}
In this paper the author considers three typical cases of wall base damp - where low-level penetrating dampness has caused problems above or below internal floor level. Many refurbished older buildings suffer damp damage as a result of unsatisfactory wall base detailing. Much time and expense is found to have been wasted when an otherwise successful project is seen to suffer early damp damage.

The author considers this kind of damp problem much more common than 'true rising damp', and invites readers to email him with their own suggestions for remedying the damp.
\end{abstract}

\section{Keywords:}

damp-proof course, wall base damp, low-level penetrating dampness, rising damp, people's damp, damp diagnosis, basement damp

Ralph Burkinshaw

Dampness Investigation Consultant Dampness Investigation Services

32 Acland Crescent

London SE5 8EQ, UK

Tel: +44 (0)20 77374868

E-mail:

rf.burkinshaw2@ukonline.co.uk

\section{INTRODUCTION}

Over the past 40 or more years, it has been common practice for some in the property industry to label nearly every patch of damp just above a ground floor skirting board as 'rising damp'. That 'diagnosis' has been made usually from visual evidence and moisture meter checks alone.

Standard treatment of 'rising damp' has usually been the insertion of a chemical-injected damp-proof course (DPC) together with the application of protective solid plasters as a final defence to mask the dampness. This might well be termed 'damming the damp'. This kind of remedy may not target the root cause of the dampness, but merely mask the symptoms and eventually the dampness may resurface. Money spent on chemicalinjection DPCs and the associated protective replastering in many cases might be more usefully spent on a remedy more targeted to the root cause.

It could also be argued, however, that there are some occasions when such damming of the damp might be the only realistic alternative-for 
Possible damage from high external levels example, when a dry wall surface suitable for decoration is needed quickly. There is sometimes not the time or the resources to follow through a more thorough building examination and long-term cure.

During the 1990s a number of surveyors and researchers strongly challenged quick-fix solutions to dampness problems, with one or two even claiming rising damp to be a myth. But the debate was to a certain extent groundless, as, to my knowledge, there was never a workable definition of 'rising damp' until the following was published (Burkinshaw and Parrett, 2004):

'Where moisture travels upwards through the pore structure, or via small fissures or cracks, or as water vapour, against the forces of gravity, typically up a wall or through a floor from a source below the ground.'

Certainly, many low-level dampness problems have resulted from low-level dampness penetration or plumbing leaks. In such cases, dampness does indeed rise or soak upwards, but usually from around ground level. For the purpose of this paper, any dampness found at a low level in house walls is termed 'wall base damp'.

Whether or not such problems should be described as 'rising damp' is not really the most important issue. When dampness is found, and it is causing a problem for the building or users of the building, more than anything else the cause needs to be found together with a solution to put the problem right. It is less of an issue whether the damp should be labelled 'rising damp', 'penetrating damp' or any other 'damp', and there should be no automatic remedy for any cause of dampness.

Most houses built since 1877 actually possess a horizontal DPC and, if this is intact, dampness from below the ground only would be a real threat on a very wet site. Unsuitable changes in and around the building, however - such as the raising of external ground levels - increase the risk of lowlevel damp penetration, but it is the height of external ground in relation to vulnerable floor timbers or easily reachable plasters and decorations that is the key factor. Whatever the height of the horizontal physical DPC it would not prevent lateral damp penetration. Timber will now be less high up in relation to external ground level, floor ventilation will be compromised, routes for damp penetration through the wall base will be created via air vents and poorly maintained masonry and the floor oversite level or 'solum' now will be lower compared to the external ground level, making it more likely to become a water collection zone. Water splashing and pooling from rain is free water in significant quantities and free water can soak and trickle into porous low-level masonry at will.

In a traditional masonry house, dampness may be prevented from causing problems by subtle combinations of wall base detailing. The first line of defence may be the dual protection of a horizontal damp proof course and a vertical wall base plinth. This in effect creates protective ' $L$ ' shaped damp protection. In addition to these two 'barriers', moisture may evaporate out on both sides of the wall base, ie within the floor void and externally. Wall base finishes and the amount of sub-floor ventilation will influence the amount of that evaporation. The way in which the wall base 
A new concept: the 'ledge effect' takes in and gives out moisture needs to be carefully balanced to keep damp at acceptable levels. Rainwater splashing and collecting at the intersection of a wall and the ground should not be allowed to soak too readily into the wall base around ground level, and an effective plinth (or perhaps dense low level masonry), coupled with good surface water drainage, is the key.

The intersection of a wall base and the ground creates a 'ledge effect' where lateral water penetration can be a problem. This effect can be seen at all heights of a building, eg just above a decorative cornice, near the top of an abutting boundary wall, or even where builders' rubble is piled up against a wall. The way moisture may be managed by drainage, evaporation or barriers was well described and illustrated by Peter Bannister at the Aston University Conference on 3 November, 2004: 'Dampness and Decay in Buildings - The Whole Solution'.

The Building Research Establishment (BRE) has over the years largely ignored low-level lateral dampness penetration, choosing to emphasise the threat of dampness from the ground or dampness penetration into the building at a higher level, for example, on exposed south-west elevations or via poor detailing of openings, or poorly installed cavity fill insulation.

Low-level dampness penetration at the wall base is usually only referred to in the context of frost damage, where less durable bricks could become wet below a DPC and be damaged by the expansion forces from freezing. In the author's view, the BRE usually over-emphasises and misconstrues 'bridging'. It is always assumed that a huge store of water is ready and available — waiting in ambush from a below-ground source — to track, ie 'bridge', around a DPC via porous renders and plinths to cause damp havoc above it. It may be more likely that this moisture was mainly soaking into and collecting in masonry near ground level from the vast volume of water splashing, pooling and soaking into the wall base every time it rains. Again, in this case, the position of the horizontal DPC may be less of an issue.

\section{LOW-LEVEL DAMPNESS PENETRATION - THE PEOPLE'S DAMP PROBLEM}

This, perhaps unglamorous, humble and certainly understated damp problem manifests itself in thousands of houses up and down England under owners' very noses. It could be described as the people's damp problem.

The buildings of England are sinking. Just sit in a school playground surrounded by Victorian school buildings and one really gets the strange feeling of being encircled by sinking ships. The brick walls seem to be engulfed by the ever-rising tide of wavy tarmac. Walk along any line of older terraced houses and nearly every house will be semi-submerged by rising patios and machine gunned just near the waterline by dampcoursing drill holes. There now follow some recent cases of "wall base damp', accompanied by a method of diagnosis (Figure 1).

\section{Case Study 1 - North London}

Case Study 1 considers an Edwardian house suffering localised dampness noticed by the occupier just above the front bay skirting (Figure 1). The damp problem was discussed over the telephone with the client who 


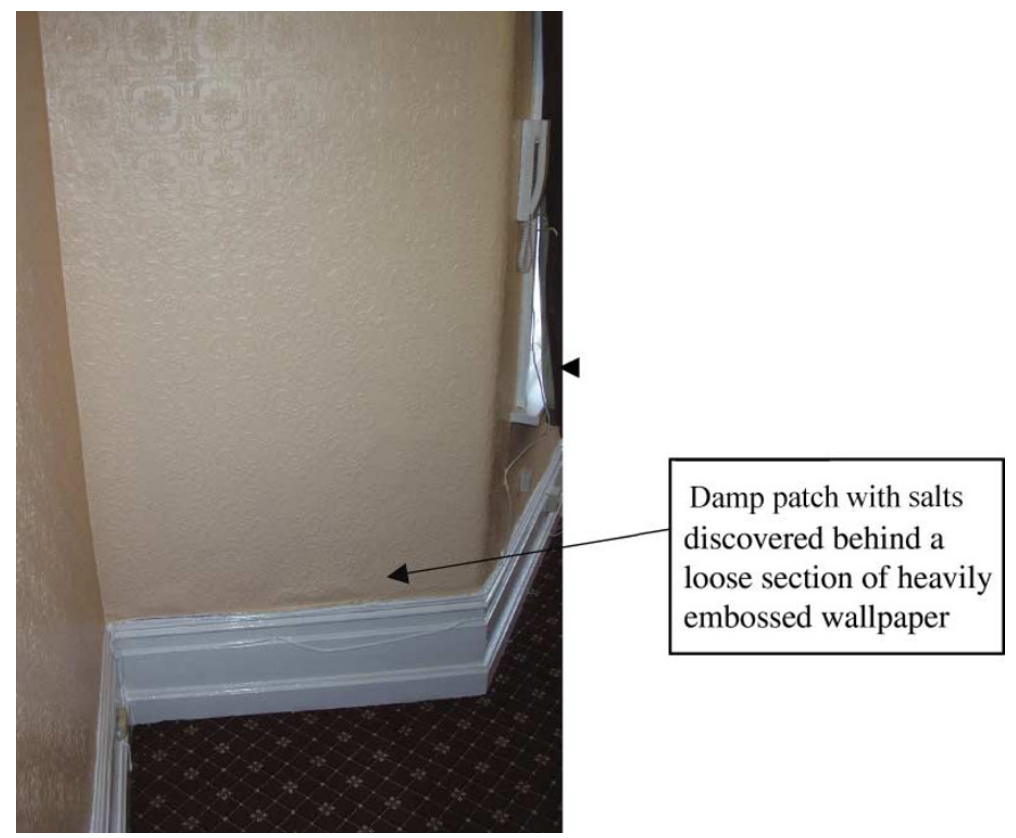

Figure 1: Dampness to the left of a front bay, visible once a heavy filing cabinet had been moved

\section{Diagnosis by post?}

\section{Proactive surveying the key}

agreed to post a salts scraping for analysis. The sample duly arrived - and only just enough - a meagre half-teaspoonful. The sample tested negative for nitrate and chloride, so contained sulphates probably from the construction materials themselves and most particularly from internal wall plasters. Before even arriving on site I had a hunch, but just a hunch (ie not a preconceived diagnosis) that the dampness might not have originated from below ground. It can be tempting sometimes to offer copious practical advice over the telephone to a client, but one runs the risk of talking oneself out of a fee-paying investigation.

On site a heavy and quite daunting filing cabinet was moved back and the salty plaster in the room corner examined. It was certainly damp - from high moisture-meter readings in the plaster and skirting board - and at this stage it could be thought to be 'rising damp'. It is quite tempting to then just pack up and go home, collect the fee and pass on responsibility for diagnosis to the remedial treatment industry. But Sherlock Holmes would not be so slack or hasty — one should linger, and ask more questions of the building, which requires lateral thinking.

In most cases, one should think laterally to relate a dampness epicentre to the context of the building plan and all possible moisture sources one could plot on it, especially at the earlier stage of an investigation. Knowing the wall plasters to be salt-laden, I knew that taking moisture-meter readings in the plaster just above the skirting might not help to identify an epicentre of the dampness. Once salts are present in masonry/plaster materials, readings are often at a maximum $100 \mathrm{R} / \mathrm{R}$ in spite of varying relative moisture content (see Burkinshaw, 2002). But by taking pin-probe readings at regular intervals all along 


\section{Damp meters help find the epicentre of dampness}

\section{Sketches help you diagnose damp and design remedies}

the front skirting boards, distinct zones of high readings to each side of the front bay were soon discovered.

From the methodical use of a moisture meter, 'invisible dampness' had now been identified to the right side of the bay, even though no visible symptoms of dampness were apparent. It is likely that in time walling to the right side of the bay would also show salt accumulation from evaporation of moisture that had moved through the material.

It seemed likely that there was a link between high dampness readings on each side of the bay and the rainwater pipes noted from the walkover inspection earlier. But more positive proof of the link was needed. It was now necessary to simulate rainy conditions so a watering can was used to pour water down the main front rainwater downpipes via an easily reachable lower gutter - water streamed over the yard to form a pool to the right side of the bay. Water could be seen trickling downwards between the wall and paving and also through cracks between the crazy paving stones. Thus more evidence was acquired and with it the likelihood that a diagnosis was close.

Logic led one to conclude that there was a link between the dampness at two positions and the splashing rainwater at the same two positions. This is a lateral analysis of the dampness. Scanning the roofing to the property, I noted that the right-hand downpipe also accepted rainwater off the right-hand property's roof, so there would be a greater overload of surface rainwater to the right side of the bay. All the pieces of the diagnostic jigsaw then seemed to fit.

It is not too difficult to confirm moisture condition using surveying instruments, although the drilling of samples for carbide testing can be time-consuming. Confirming the origin of the moisture is harder still; however, designing, specifying and installing a workable remedy to suit the building, its user and client needs, is probably the hardest nut of all to crack.

To produce a workable remedy and to further understand how the rainwater build-up could affect the wall base, a sketch was made, quite quickly proportionally drawn on site, but later drawn to scale back at the office. Any surveyor would be able to understand this damp problem, now that there is a scale cross-sectional drawing to study. At this stage of the investigation, one thinks vertically (Figure 3 ).

I am a great believer in developing sectional sketches to diagnose damp and I now prepare them for nearly every investigation. Once drawn, the sketch can earn fees when a detailed remedy specification is required. One should make sure to measure the difference between internal floor height and external ground level and check how near structural timber is to the wet wall base zone. In Case Study 1, I advised providing a proper rainwater gully on each side of the bay with connecting drain pipework to the nearest available inspection chamber which, in this case, was adjacent to the front boundary.

While watching the flooding rainwater pipe produce a large pool of water to the right-hand side of the bay, the author also noticed water trickling down into the sub-floor via an airbrick which was half buried in the yard from successive new yard surfacings (Figure 2). Consequently, 


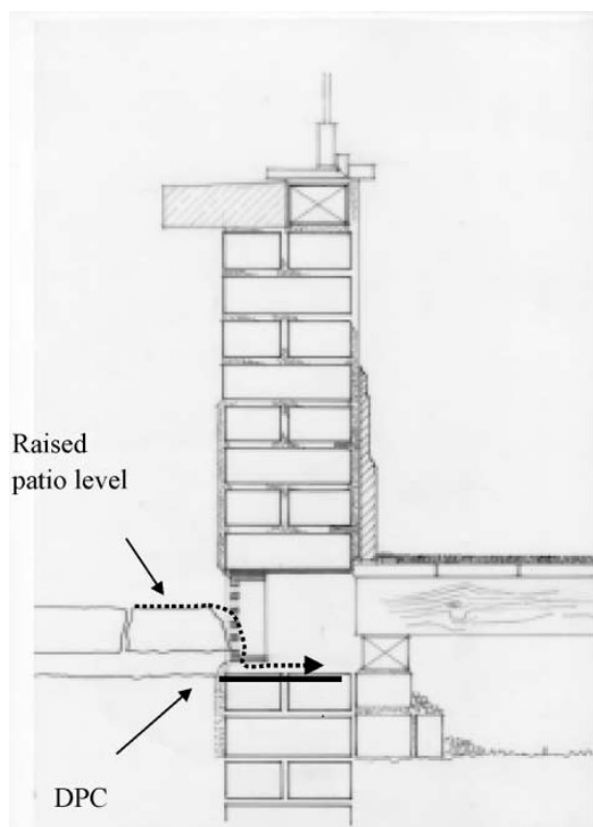

Rainwater tracks in via airbricks

over DPC

to threaten

floor timbers

Figure 2: Low-level dampness penetration via airbricks

a drained channel detail also needed to be designed and installed around the bay to locally reduce high external surface levels.

I was unable to find the horizontal DPC. But at whatever height and in whatever condition it would have made little difference. Unsatisfactory rainwater disposal arrangements, coupled with poor surface water drainage of front yard, had dictated the moisture condition of the wall base (the likely DPC position is marked as a dark black line in Figures 2 and 3). Surely, this example of damp should be called 'U-turn damp'.

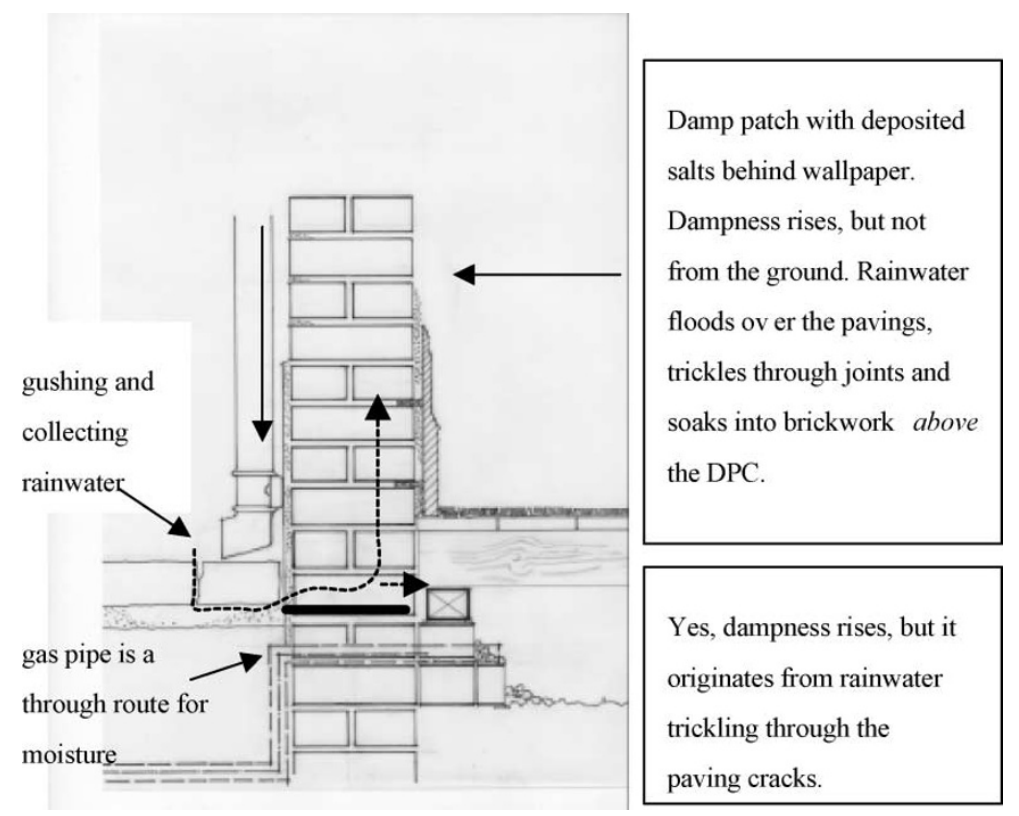

Figure 3: The threat from low-level penetrating rainwater 
The pragmatic method of diagnosis
How the diagnosis was reached

- Salt damp discovered above skirting

- Salts tested, nitrate and chloride negative

- Focus of dampness checked using a moisture meter (dampness to sides of bay identified)

- Test using poured water confirms low-level rainwater penetration via yard cracks and floor vents on each side of the bay

- Floorboard lifted to facilitate the taking of measurements for a vertical section sketch, as well as making possible a close inspection of vulnerable sub-floor timber

- Wall base detailing drawn to clarify the likely pathway for soaking moisture and to help devise and specify remedial work

- Moisture condition monitored to confirm diagnosis and, hopefully, the success of the remedy (see Burkinshaw, 2004 for guidance).

\section{Case Study 2-Oxfordshire}

In Diagnosing Damp (Burkinshaw and Parrett, 2004), the authors describe how there often may be more than one source of moisture causing a damp problem. It is often useful to know which source is dominant, or the 'lead source'. Such a combination of moisture sources was found in a semidetached house in Oxfordshire.

As can be seen from Figure 4, surface water could enter the floor void and low-level brickwork via an airvent as in Case Study 1. Collected debris from past replastering along the edge of the sub-floor void acted as a 'reservoir' for moisture.

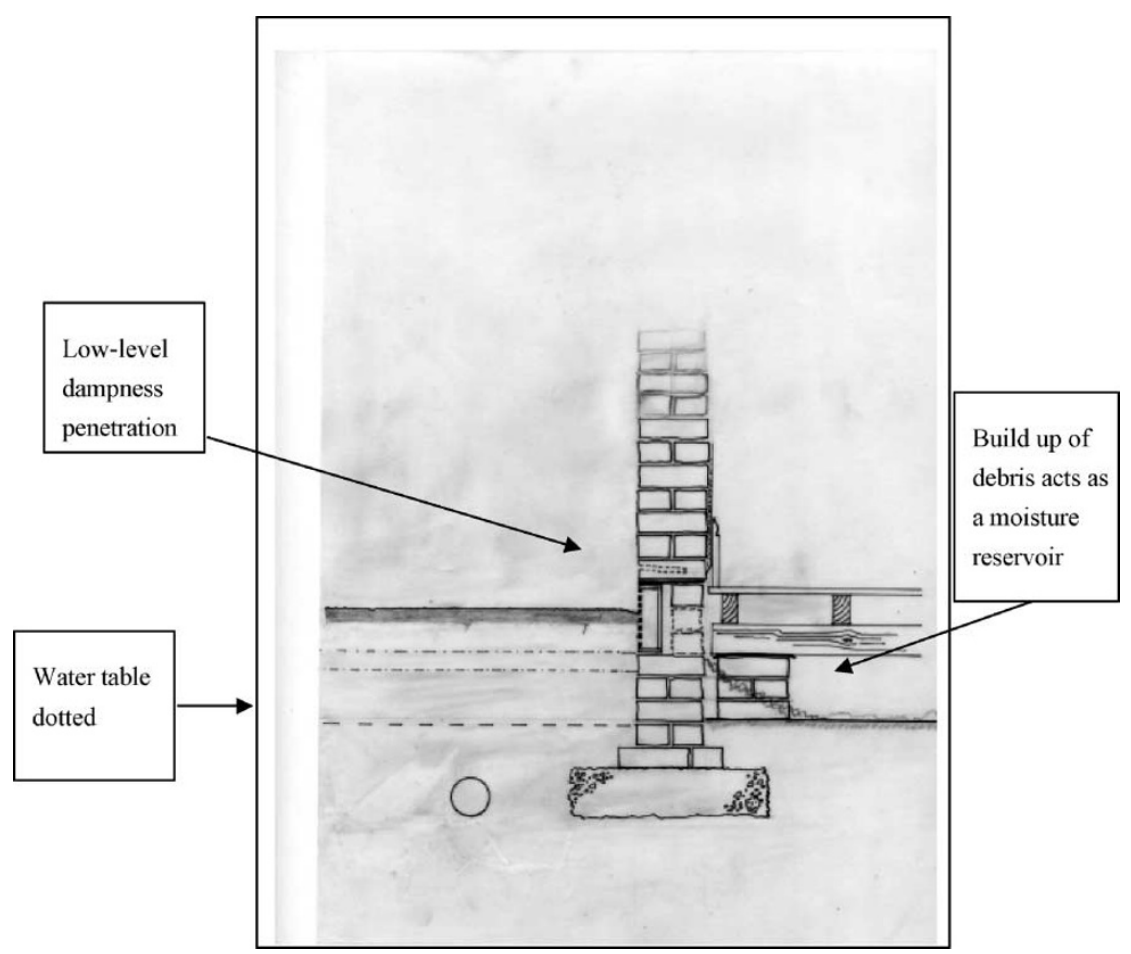

Figure 4: Height of the water table threatens the sub-floor void 
How would you check water table height?
In Case Study 2 there were two moisture sources to confuse. In addition to the low-level dampness penetration there was a significant seasonal effect from a high water table. The water table rose very high in the winter, creating very humid conditions in the sub-floor void, threatening structural timber. As can be seen in Figure 4, the water table rose up virtually to the sub-floor oversite or 'solum' level. The whole sub-floor void became very hydrated, with condensation forming on the brick sleeper wall surfaces, and timber joists, wallplates and boards became significantly damp and likely to rot. The question was, should a remedy be designed to target the low-level damp penetration or to drain the obviously very wet site?

Here is an example of 'double damp' from two distinct moisture sources. First, low-level damp penetration from raised external ground levels occurred due to nothing more than rather thoughtless property 'improvements'. Secondly, hydration of the sub-floor occurred due to a persistently high water table during the winter season. Such a traditional wall and floor construction simply could not cope with a wet site, and the height of the water table had probably been increasing over the years. This would have been an unforeseen risk when the building was designed and built a century ago.

The low-level damp penetration caused structural timber in contact with wetted masonry to rot. To remedy the low-level damp penetration, one might consider locally reducing the yard level by creating a shallow drained channel around the building perimeter. A cementitious plinth could then be applied to the wall base. To lower the water table a much deeper perimeter site drainage trench would be needed, linked ideally by gravity-run, field drainpipes to a convenient inspection chamber.

But which of the two sources is the 'lead source'? One will never know. To isolate the lead source requires the remedy of one source only, followed by monitoring the building's moisture condition over two years because traditional fabric is very slow to respond to remedy. There is neither the time nor the resources to devote to such a long-term experimental monitoring initiative. One needs to be pragmatic and put in place a remedy to control both moisture sources. Subsequent close monitoring of masonry and timber moisture conditions will help to evaluate the success of the applied remedy.

\section{Case Study 3-East Dulwich, London}

Floor timber near the hearth had rotted extensively from close contact with wet hearth fill. Boards spiked to the joist and trimmer timbers around this Victorian hearth had remained in situ as permanent shuttering of what was a mass of loosely bound clinker fill. This rot damage was not apparent until some floorboarding was lifted near the chimney breast. Two horizontal DPCs had failed to prevent moisture soaking through the chimney breast and hearth masonry, so additional damp protection was needed. Once some boards were lifted, carbide tests to assess moisture content were certainly not required as masonry and hearth fill was very visibly soaking wet. In this particular case, it was not me who actually lifted key floorboards. A nervous occupier was hesitant during the initial 


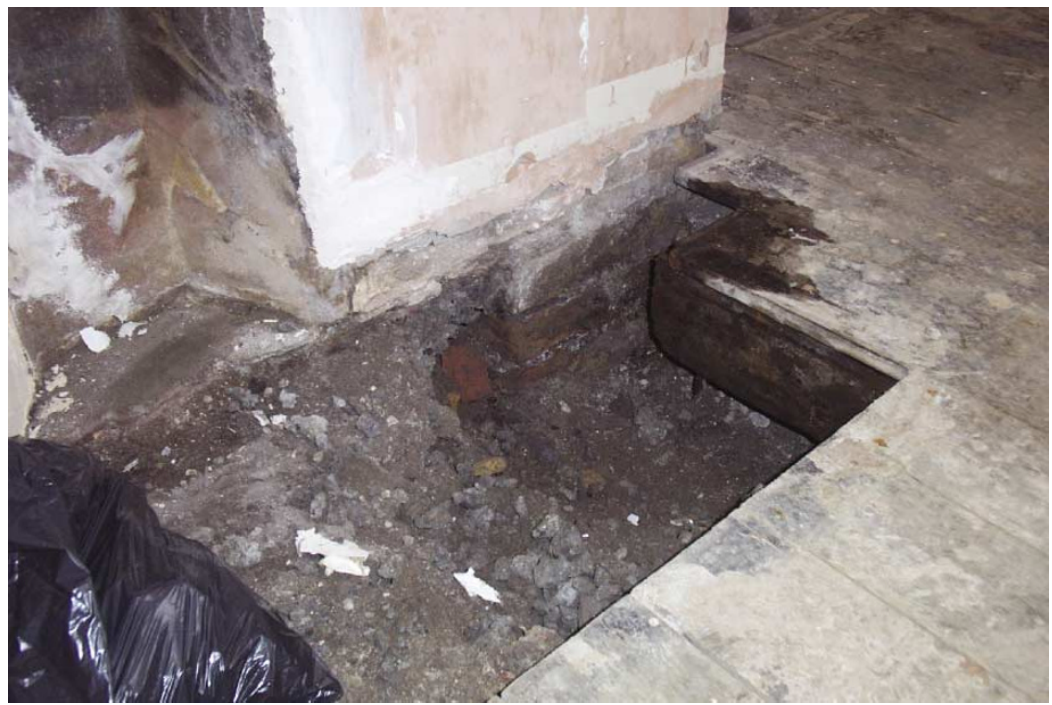

Figure 5: Wet rot to joists around the hearth

\section{Can floorboards be lifted without causing damage?}

survey and afraid of any denting I might cause from the necessary floorboard lifting. So in a subsequent report I clearly stated the importance of furthering the investigation by inspecting more thoroughly under the floor. I received a telephone call a day or so later from the by-now-anxious client: 'You'll never guess what I've discovered under the floor. I lifted floorboards and found everything wringing wet - you must come and have a look!'. So this investigation was extended yet further as Figure 5 shows.

Once a scaled sketch was drawn (Figure 6), it was easy to see how moisture was almost certainly tracking through the chimney breast and

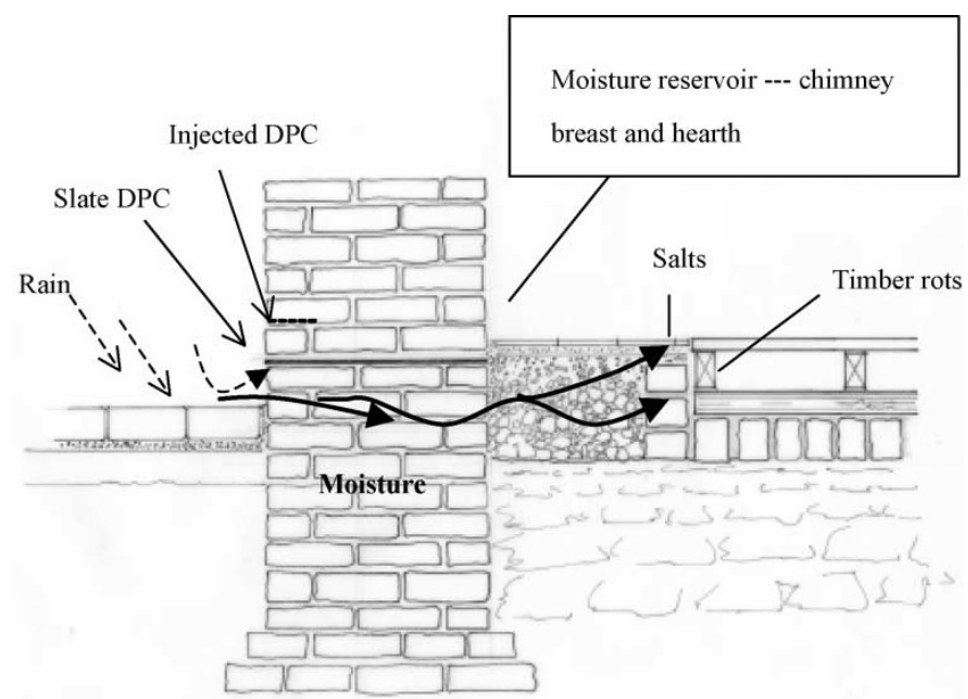

Figure 6: Penetrating damp tracks into a huge moisture reservoir 
Two horizontal DPCs couldn't prevent damp penetration soaking into the hearth to rot flooring timbers as seen in Figure 5. The hard pavings caused water to splash against the unprotected masonry, pool against the wall base and soak through between paving and brickwork. The $150 \mathrm{~mm}$ minimum height of a horizontal DPC does not prevent the brickwork below the DPC from becoming soaked by bouncing rain.

Possible remedies could be the application of a wall base cement plinth from ground to DPC height, or to create a drained channel along the wall base filled with pea shingle to reduce rain splash.

In this case an original horizontal slate DPC plus an additional chemical injected DPC were not enough to keep the wall base acceptably dry, and so protect the floor timber. What was needed was additional wall base protection by way of vertical protection (plinth) or an alternative paving detail to reduce wetting by rain splash or pooling water. In this case, moisture was soaking through laterally below the existing slate and the new injected DPC (ie under two DPCs) so I termed this 'diving damp'.

\section{Remedy}

Return visits are needed to evaluate the success of a remedy

New floor timber was installed, carefully built without any contact with potentially wet masonry. I recommended rebuilding the hearth to an improved specification. It would be a fire risk to remove a hearth with the fireplace still potentially operational. It is surprising just how many fireplaces are used for a coal or wood fire during the festive winter season. Also, a section of floorboard was left unnailed so that it could be raised in a few months' time to see if the hearth had dried satisfactorily; ie some traditional 'monitoring' was all that was needed. For some advice on the range of monitoring techniques available to surveyors please refer to Burkinshaw (2004).

\section{SUMMARY POINTS}

'Blue riband' defects have not been considered in the above cases, but these are important nonetheless, and can be discovered in many older houses up and down the British Isles.

- A physical horizontal wall DPC on its own may not provide adequate dampness protection to the wall base and adjacent timber floor members.

- A horizontal wall DPC controls movement of moisture from above and below.

- Installing multiple horizontal DPCs may still not prevent low-level lateral damp penetration.

- A horizontal wall DPC controls upward movement of moisture that has penetrated the wall base between the ground and the DPC, as well as controlling or sometimes stopping moisture originating from below ground. It should not be forgotten that much of this localised belowground moisture can result from inadequate rainwater disposal arrangements around the building. Just consider the amount of rainfall per square metre over the whole site compared to the sheer concentration of rainfall load at the bottom of each downpipe. 
- In traditional houses built with solid walls, a vertical DPC may be needed below the horizontal DPC. Traditionally, this has been by way of a cementitious plinth or sometimes vertical slatework or asphalt.

- Even simple damp problems can be a mystery and a challenge at the early stages of investigation on site until all the pieces of the jigsaw finally piece together. Once diagnosed, all the symptoms presented can seem as clear as day.

- Pro-active surveying is the order of the day. Always lift floorboards, take measurements, pour water, make observations and analyse findings.

- A methodical manner should be adopted on site. Explain what is planned and how it might help to drive the investigation. Most occupiers will allow the surveying to be taken further than previously thought possible. Stained wallpapers and salt-laden plaster is already defective and became defective months or years before a surveyor arrived on site to scrape or drill it.

- Dampness investigation is not just checking with a moisture meter just above the skirtings near the end of a building survey, it is integral to the survey from chimney pot down to foundations. Dampness is always cited as the commonest cause of building defects.

- Diagnosing damp is time-consuming and sometimes invasive. But spending hundreds of pounds on further investigation of dampness may save thousands. Many homeowners, facing a 'nightmare damp' scenario from flood, mould, rot, or salt-damaged plaster, now wish they had invested in a fuller investigation of dampness prior to purchase.

- Drawing a sectional sketch enables one to understand the construction technology of the wallbase, which will help diagnose the cause of the dampness and formulate a remedy. It is useful to compare the detailing as found with current building regulations or with examples of more traditional construction that has proved satisfactory over the years.

- Few chartered surveyors possess the resources in terms of time, equipment or expertise to carry out intensive laboratory-style investigation such as 'the sampling method' offered in BRE Digest of 1986 on rising damp, so practical site investigation methods such as this paper champions is needed.

\section{'BASEMENT DAMP'}

So now it is over to the readers for their remedy challenge. This paper has concentrated on low-level dampness penetration to older properties with raised timber floors. Now it is time to look at formulating strategies for remedying solid floor 'basement damp'. Many readers will have seen cases of such basement damp in the lower ground floors of traditional buildings. The typical problem building is usually threeor four-storey with a flight of steps up to the ground floor, and side steps down to a lower yard with a separate flat entrance. To remedy the damp problem, specialist waterproofers often strongly promote the systems they themselves install (as is the way of the world). There are streets and streets of basement damp in such locations as Maida Vale or Kilburn and no doubt every other town in the UK. Surveyors need to 


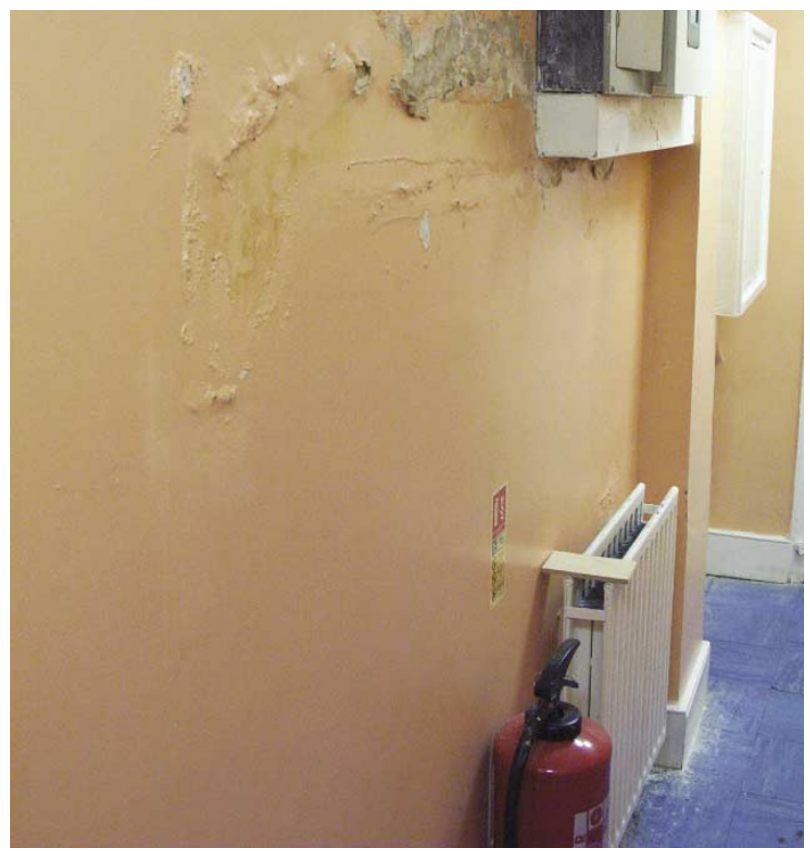

Figure 7: A typical band of 'salt damp' has developed above the top line of a protective cementitious render (who still says that rising damp does not exist?)

get to grips with it, as too often remedies are not closely tailored to the building and occupants' needs.

Typical features of 'basement damp' include the following.

- Parts of the walls and floors will be below outside ground level.

- There will be salt damage to wall plasters (see Figure 7 for typical damage).

- Skirtings may be rotten.

- Walls may have been replastered with cementitious renders, sometimes incorporating a waterproofer.

- The floor in most cases will be retro-fit, solid-ground-bearing concrete.

— Front and rear yards may be flanked by retaining walls.

\section{The challenge}

Readers should consider a case they have come across and tell the Journal about it. Write down a few notes regarding the symptoms of the dampness, how the damage was surveyed etc, include photographs of the building and problem if available. Describe how the dampness was remedied and whether the remedy succeeded in producing a dry home. Send ideas in to the author or the Journal editor by email or in the post. Experiences and ideas will be incorporated into a forthcoming paper entitled: 'Getting to grips with basement damp!'. The aim is to share experiences of this common building ailment and help to increase understanding by specifying more successful remedies. 


\section{References}

Building Research Establishment (1986) Rising damp in walls: Diagnosis and treatment, BRE, Watford.

Burkinshaw, R (2002) 'What is the moisture meter trying to tell us?', Structural Survey, 20(5).

Burkinshaw, R (2004) 'Which instruments should surveyors use to monitor moisture condition?', Structural Survey, 22(1).

Burkinshaw, R and Parrett (2004) Diagnosing Damp, 2nd edn RICS Books, London, UK.

\section{Note}

All drawings and written material in this paper may only be copied/reproduced/used in connection with any other published work or paid activity with the express permission of the author, Ralph Burkinshaw. 